\title{
Crash Simulation of a Vertical Drop Test of a Commuter-Class Aircraft
}

\author{
K. E. Jackson* and E. L. Fasanella* \\ *U.S. Army Research Lab, Vehicle Technology Directorate, MS495, NASA Langley Research Center, Hampton, VA 23681
}

\begin{abstract}
A finite element model of an ATR42-300 commuter-class aircraft was developed and a crash simulation was executed. Analytical predictions were correlated with data obtained from a $30-\mathrm{ft} / \mathrm{s}(9.14-\mathrm{m} / \mathrm{s})$ vertical drop test of the aircraft. The purpose of the test was to evaluate the structural response of the aircraft when subjected to a severe, but survivable, impact. The aircraft was configured with seats, dummies, luggage, and other ballast. The wings were filled with $8,700 \mathrm{lb}$. $(3,946 \mathrm{~kg})$ of water to represent the fuel. The finite element model, which consisted of 57,643 nodes and 62,979 elements, was developed from direct measurements of the airframe geometry. The seats, dummies, luggage, fuel, and other ballast were represented using concentrated masses. The model was executed in LS-DYNA, a commercial code for performing explicit transient dynamic simulations. Predictions of structural deformation and selected time-history responses were generated. The simulation was successfully validated through extensive test-analysis correlation.
\end{abstract}

\section{INTRODUCTION}

This paper describes the development and validation of a full-scale finite element model of an ATR42-300 commuter-class aircraft for crash simulation. The model was developed prior to the vertical drop test of the aircraft and analytical predictions were generated for correlation with the experimental data. Model validations, such as described in this paper, are necessary to gain confidence in the application of explicit transient dynamic finite element codes for crashworthy design and certification. In fact, the "validation of numerical simulations" was identified as one of the five key technology shortfalls during the Workshop on Computational Methods for Crashworthiness that was held at NASA Langley Research Center in 1992 [1].

In 1998, the U.S. Army Research Laboratory Vehicle Technology Directorate (ARL-VTD) entered into an Inter-Agency Agreement (IAA) with the Federal Aviation Administration (FAA) William J. Hughes Technical Center for the purpose of validating crash simulations of airframe structures. As part of the IAA, finite element models were constructed of two 10-ft. (3.05-m) long Boeing 737 (B737) fuselage sections, one outfitted with an auxiliary fuel tank mounted beneath the floor and the other with two different overhead stowage bins and luggage. Vertical drop tests of these two fuselage sections were performed at the FAA Technical Center in 1999 and 2000, respectively $[2,3]$. These tests provided a valuable opportunity to evaluate the capabilities of computational tools for crash simulation through analytical/experimental correlation. Full-scale three-dimensional finite element models of the B737 fuselage sections were developed using MSC.Dytran [4], a commercial explicit transient dynamic code, and simulations of the vertical drop tests were executed. The model predictions were successfully validated through detailed test-analysis correlation, as documented in References 5 through 7.

In 2003, the IAA was extended for an additional five years, through 2008, and the model validation work entered a new phase with the development of a full-scale finite element model of the ATR42300 aircraft. For this simulation, the model was developed using the pre-processing software package, MSC.Patran [8], and the final model was executed using another commercial code, LSDYNA [9]. The FAA performed a 30-ft/s $(9.14-\mathrm{m} / \mathrm{s})$ vertical drop test of the aircraft to determine the impact responses of the airframe, floor, seat tracks, seats, dummies, and high-wing fuel system. Recently, the FAA has proposed dynamic performance criteria for seats in commuter aircraft that were based on empirical information obtained from prior airplane crash test data, which did not include airplanes representative in size of commuters. Consequently, this drop test was performed to provide impact data to evaluate the seat standards for this category of aircraft. The experimental program, model development, and test-analysis correlations are presented in subsequent sections of the paper. 


\section{EXPERIMENTAL PROGRAM}

On July 30, 2003, a 30-ft/s $(9.14-\mathrm{m} / \mathrm{s})$ vertical drop test of an ATR42 aircraft was conducted using the Dynamic Drop Test Facility located at the FAA Technical Center in Atlantic City, NJ. A pre-test photograph of the test article, raised to the drop height of $14 \mathrm{ft} .(4.3 \mathrm{~m})$, is shown in Figure 1. This twin-turboprop, high-wing, commuter-class aircraft was developed and manufactured through a joint effort by Aerospatiale in France and Aeritalia in Italy. The aircraft has a wingspan of $80 \mathrm{ft} .(24.4 \mathrm{~m})$, a seating capacity of 42-50 passengers, and a maximum gross take-off weight of approximately $36,800 \mathrm{lb}$. $(16,693 \mathrm{~kg})$. The drop test was performed onto a concrete surface. The purpose of the test was to evaluate the dynamic structural response of the aircraft when subjected to a severe, but survivable, impact. Particular attention was given to the seat and occupant responses to evaluate the FAA's proposed dynamic seat requirements for commuter-class aircraft.

A schematic drawing of the floor of the aircraft is shown in Figure 2. The total weight of the fullyloaded and instrumented aircraft was 33,200 lb. $(15,060 \mathrm{~kg})$. A large portion of the total weight was the 8,700-lb. $(3,946 \mathrm{~kg})$ of water added to the fuel tanks in the wing to represent fuel. In addition, 16 double-occupant aircraft seats weighing $54 \mathrm{lb}$. $(24.5 \mathrm{~kg})$ each and 3 single-occupant seats weighing approximately $20 \mathrm{lb}$. $(9.07 \mathrm{~kg})$ each were attached to seat tracks on the floor, as shown in Figure 2. Seven instrumented Anthropomorphic Test Dummies (ATDs) and 16 non-instrumented mannequins, each weighing $170 \mathrm{lb}$. (77.1 kg), were seated in various locations, as indicated in Figure 2. Ballast weights equaling $135-$ and $152-\mathrm{lb}$. $(61.2-$ and $69.0-\mathrm{kg})$ were added to some of the empty seats to represent the mass of occupants. The forward and aft storage compartments were filled with 1,450and 739-lb. (657.7- and 335.2-kg) of luggage, respectively. In addition to the ballast, two overhead stowage bins were mounted between Frame Station 30 (FS 30) and FS 34 on the right and left sides of the fuselage. The bins weighed $55 \mathrm{lb}$. $(25.0 \mathrm{~kg})$ each, 22-lb. $(9.98 \mathrm{~kg})$ empty weight plus 33-lb. $(14.97 \mathrm{~kg})$ ballast in each bin. Two cement-filled cylindrical drums were attached to the engine mounts on the wings, each weighing $1,290 \mathrm{lb}$. (585 kg), to represent the engines.

A dominant feature of this aircraft is the high wing, which is attached directly to heavy fuselage frames at FS 25 and FS 27 through four "dog bone" beams, as shown in Figure 3. The "dog bone" beams attach to brackets on the fuselage frames at a location approximately $60 \mathrm{in}$. above the floor. Four upper bracket assemblies are located on the top ends of these two fuselage frames. The measured longitudinal position of the center-of-gravity (CG) of the aircraft is approximately half way between FS 25 and FS 26, as shown in Figure 2. This measurement closely matches the CG location specified by the airframe manufacturer, as indicated in the Weight and Balance Manual [10].

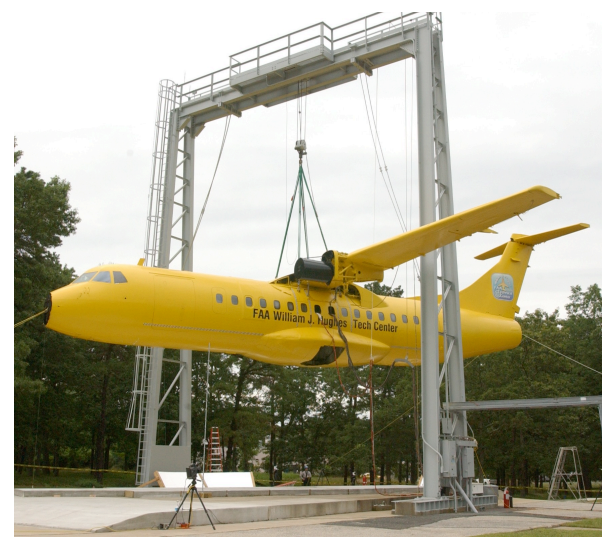

Figure 1. Pre-test photograph of the ATR42 aircraft, raised to a drop height of 14 feet $(4.3 \mathrm{~m})$.

The aircraft was instrumented with accelerometers, strain gages, load cells, pressure transducers, and string potentiometers. Test data were collected at 10,000 samples per second using two data acquisition systems, one on-board and one off-board. Of the channels available, eight acceleration responses were selected for correlation with the model. Of these eight responses, five were from 
accelerometers mounted on the floor of the fuselage cabin at locations shown in Figure 2. In addition, accelerometers located in the tail section at FS 47, the left sidewall at FS 18, and the center ceiling at FS 26 were also selected for comparison. These locations are not shown in Figure 2.

A post-test photograph showing an overall exterior view of the aircraft is shown in Figure 4. The primary damage mode to the airframe was the failure of the heavy fuselage frames supporting the wing, causing the wing to subsequently displace through the fuselage cabin. The aluminum structure supporting the wing was crushed and fractured. A post-test photograph showing a close-up view of the wing/fuselage region is shown in Figure 5 (a). Further inspection of the airframe following the test indicated that several of the seats failed, as shown in Figure 5 (b).
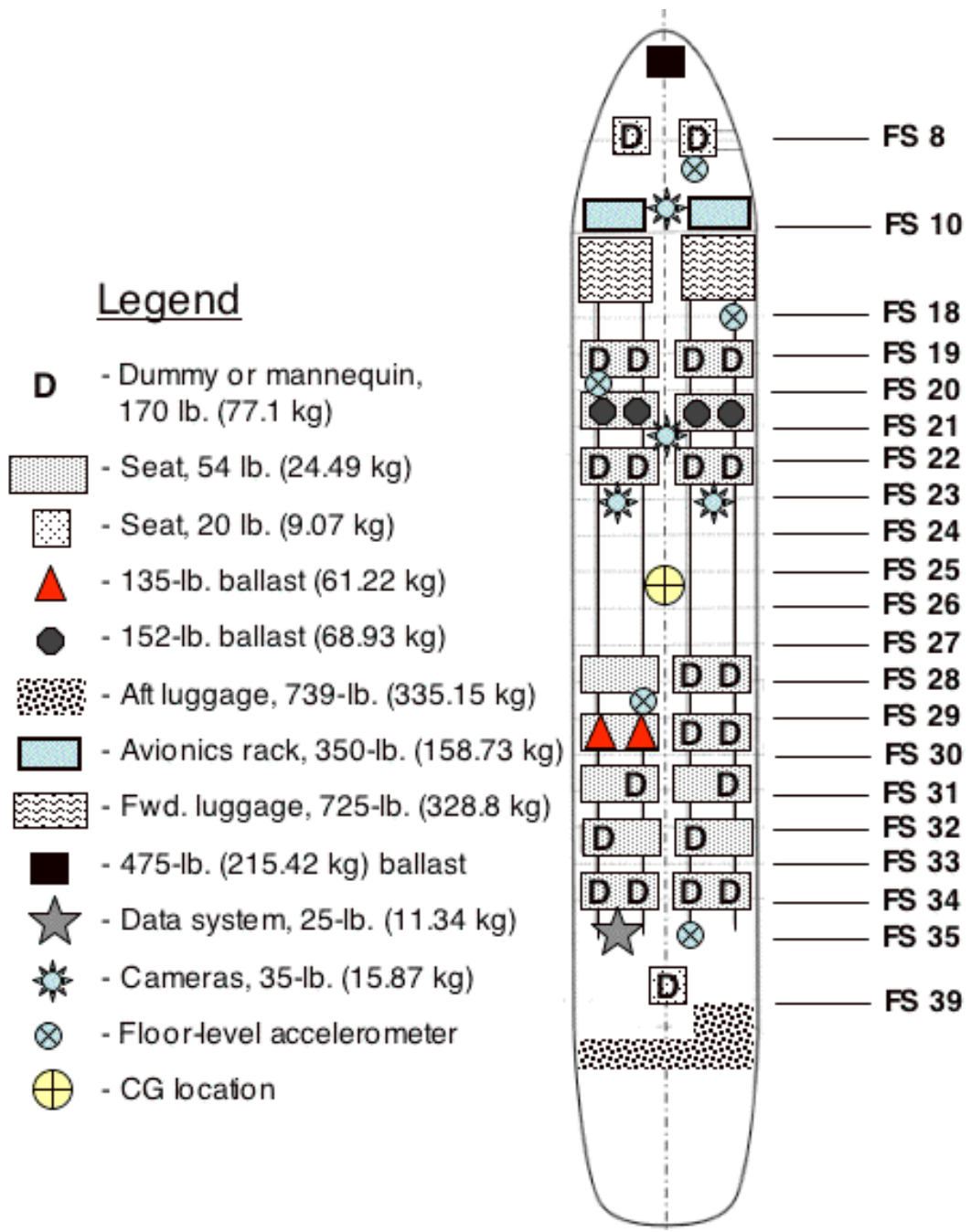

Figure 2. Floor schematic.

\section{MODEL DEVELOPMENT}

The finite element model of the ATR42 aircraft was developed from direct measurements of the airframe geometry, which were input into MSC.Patran database files. When completed, the geometry model was discretized into a finite element mesh, element and material properties were assigned, contact and initial velocity conditions were defined, and the model was executed to generate analytical predictions of structural deformation and acceleration and velocity time-history responses. The finite element model of the ATR42 aircraft, shown in Figure 6, contained 57,643 nodes and 62,979 elements including 60,197 quadrilateral shell elements; 551 triangular shell elements; 526 beam elements; and, 1,705 point elements which were used to assign concentrated masses to nodes in the model. Additional information on the model development process can be found in Reference 11. 


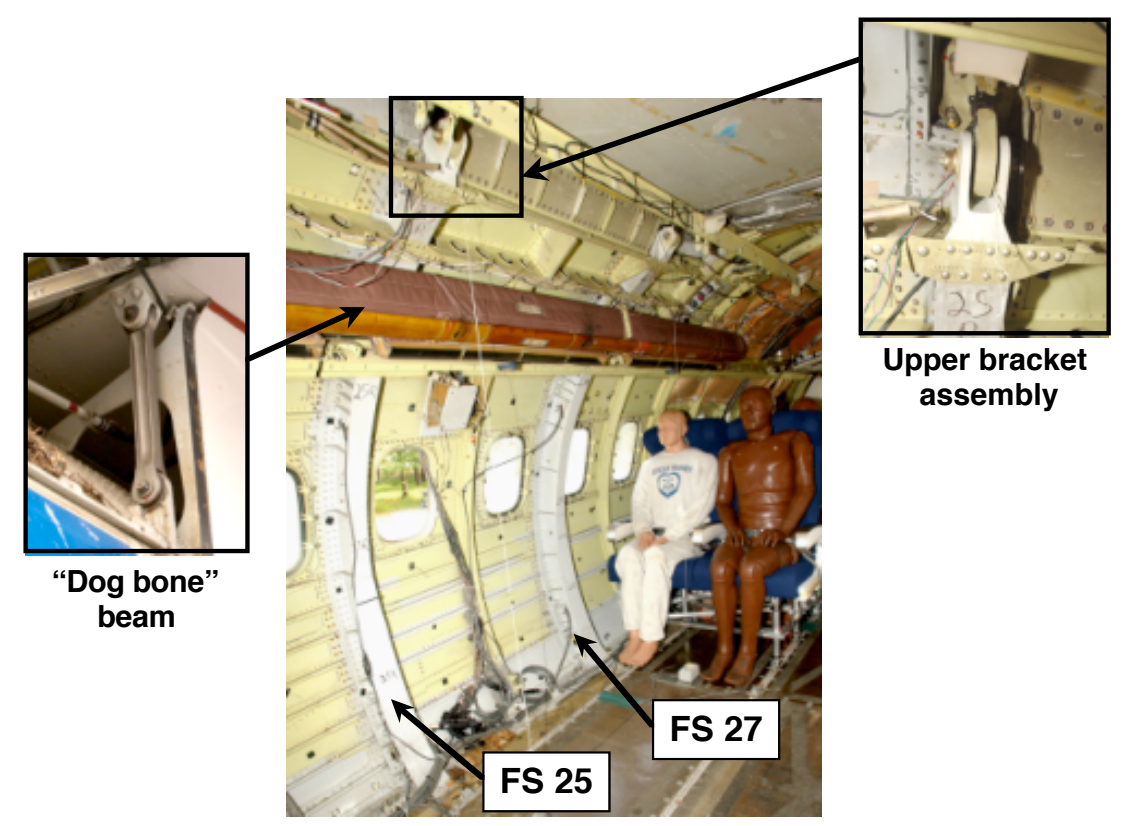

Figure 3. Photograph showing the aircraft interior at FS 25 and FS 27. Note that the locations of the "dog bone" beam and upper bracket assembly are highlighted.

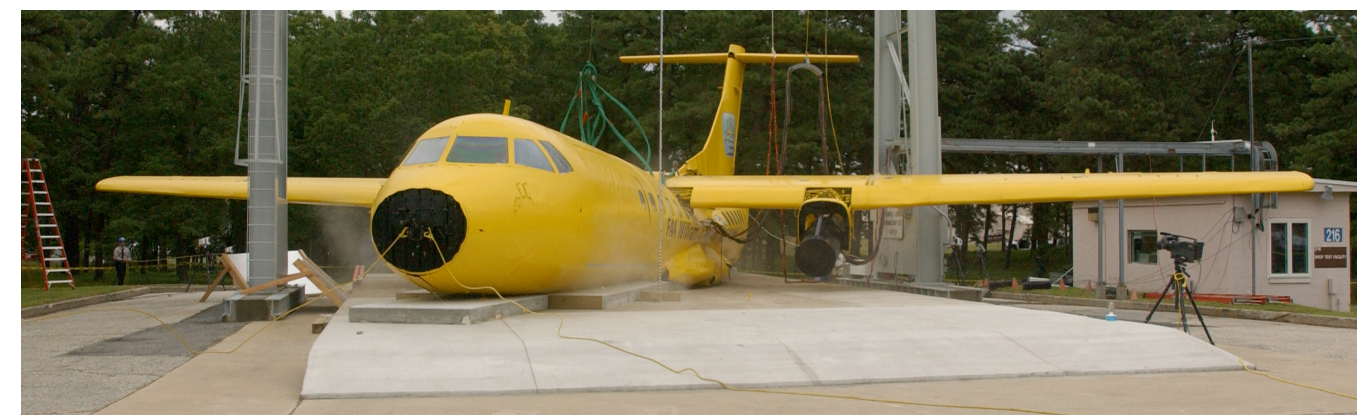

Figure 4. Post-test photograph of the ATR42 aircraft showing an overall view.

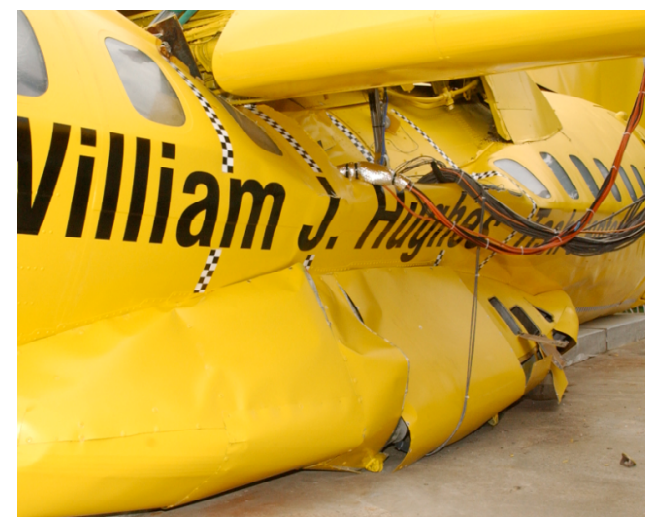

(a) Close-up view.

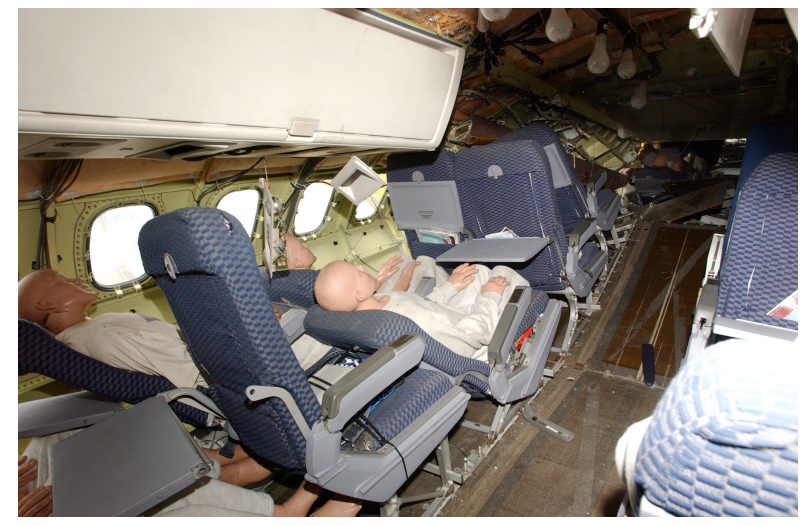

(b) Interior view.

Figure 5. Post-test photographs.

An automatic contact (CONTACT_AUTOMATIC_SINGLE_SURFACE) was specified for the model, which is a generic contact definition in LS-DYNA that prescribes that no node can penetrate through any surface in the model. An impact surface was created to represent the concrete pad beneath the drop tower. This surface was modeled as a 5 -in. $(0.127-\mathrm{m})$ thick aluminum plate, encompassing the total length and width of the aircraft, as shown in Figure 6(c). Four main material 
properties were defined in the model for aluminum Al-2024-T3, aluminum Al-7075-T6, aluminum Al-7050-T7452, and titanium Ti-6Al-4V. The properties were defined using the MAT_PLASTIC_KINEMATIC card in LS-DYNA for a linear elastic-plastic material with input values for density, Poisson's ratio, Young's modulus, yield stress, hardening modulus, and an ultimate failure strain. The specific properties used in the model are shown in Table 1. Most of the sheet metal parts, such as the outer skin were assigned material properties of Al-2024-T3. The forged metal parts, such as the fuselage frames, floor beams, and seat tracks were assigned material properties of Al-7075-T6, except for the two heavy fuselage frames at FS 25 and FS 27 which were assigned properties of Al-7050-T7452. The "dog bone" beams used to attach the wing to the fuselage frames at FS 25 and FS 27 were assigned material properties of titanium. The material property designation and mass of each component were obtained from the aircraft manufacturer's Weight and Balance Manual [10] and the material property values were estimated based on values found in MIL-HDBK$5 \mathrm{H}[12]$.

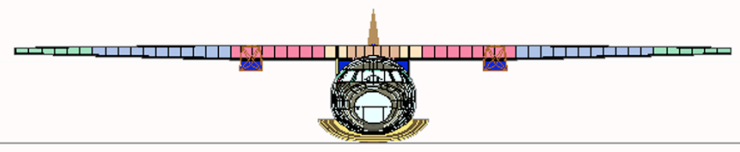

(a) Front view.

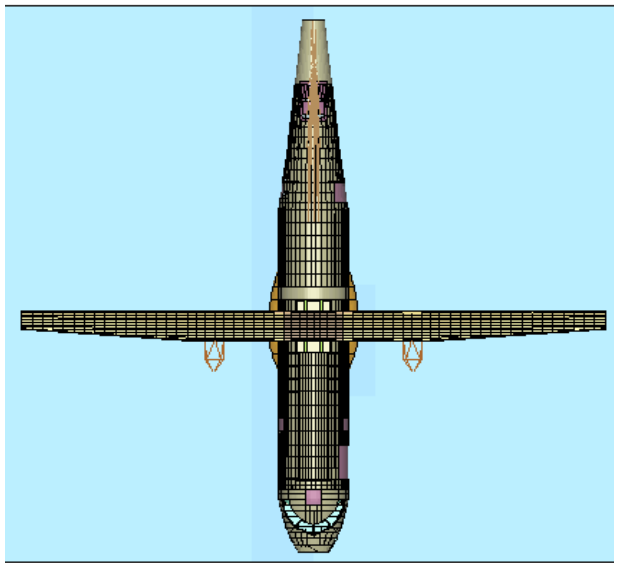

(c) Top view.

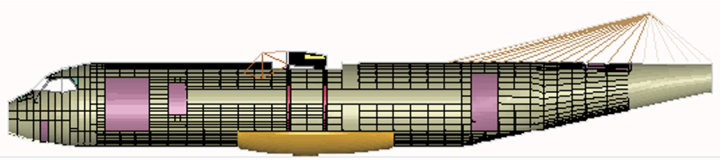

(b) Side view.

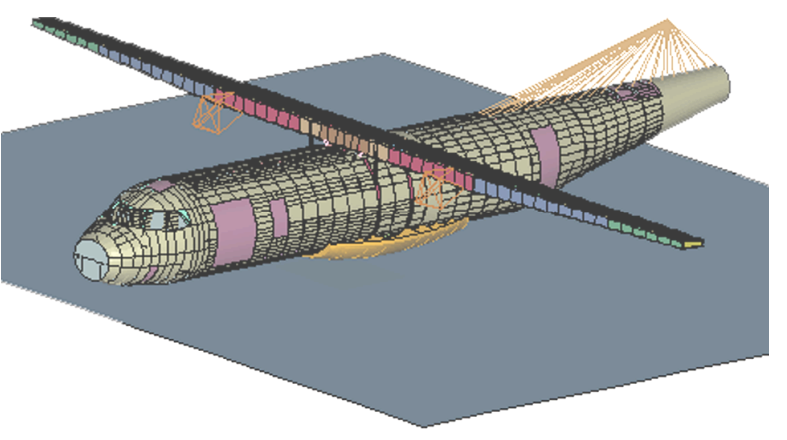

(d) Three-quarter view.

Figure 6. Finite element model of the ATR42 aircraft.

Table 1. Material properties used in the model.

\begin{tabular}{|c|c|c|c|c|c|c|c|c|c|c|}
\hline \multirow[t]{2}{*}{ Material type } & \multicolumn{2}{|c|}{ Young's modulus (E) } & \multirow[t]{2}{*}{$\begin{array}{l}\text { Poisson } \\
\text { ratio ( } \square)\end{array}$} & \multicolumn{2}{|c|}{ Density ( $\square$ ) } & \multicolumn{2}{|c|}{ Yield stress $\left(\square_{\mathrm{Y}}\right)$} & \multicolumn{2}{|c|}{$\begin{array}{c}\text { Hardening } \\
\text { modulus }\left(\mathrm{E}_{\mathrm{H}}\right)\end{array}$} & \multirow{2}{*}{$\begin{array}{l}\text { Failure } \\
\text { strain } \\
\left(\square_{\mathrm{llt}}\right), \%\end{array}$} \\
\hline & psi & $\mathrm{GPa}$ & & lb-s ${ }^{2} /$ in $^{4}$ & $\mathrm{~g} / \mathrm{cm}^{3}$ & ksi & $\mathrm{Mpa}$ & $\mathrm{ksi}$ & $\mathrm{MPa}$ & \\
\hline Al-2024-T3 & $9.62 \mathrm{e} 06$ & 66.33 & .33 & $2.59 \mathrm{e}-4$ & 2.76 & 35.25 & 243.0 & 119.9 & 826.7 & 14.63 \\
\hline Al-7075-T6 & $1.03 \mathrm{e} 07$ & 71.02 & .33 & $2.61 \mathrm{e}-4$ & 2.794 & 52.22 & 360.0 & 145.3 & 1001.8 & 4.49 \\
\hline Al-7050-T7452 & $1.04 \mathrm{e} 07$ & 71.71 & .33 & $2.64 \mathrm{e}-4$ & 2.822 & 60.0 & 413.7 & 145.3 & 1001.8 & 3.5 \\
\hline Ti-6Al-4V & $1.71 \mathrm{e} 07$ & 117.9 & .31 & $4.24 \mathrm{e}-4$ & 4.536 & 125.0 & 861.9 & 203.0 & 1399.7 & 8.0 \\
\hline
\end{tabular}

The pictures of the model, shown in Figure 6, were obtained from LS-POST [13], the post-processing software for LS-DYNA. A figure depicting the location of the point elements is shown in Figure 7. Point elements were used to assign concentrated masses representing the seats, ATDs, mannequins, luggage, fuel, and other ballast to nodes in the model. The inertial properties of the tail section were represented as a single concentrated mass, which was positioned at the approximate CG location of the tail section. The concentrated mass was connected to the aircraft model through beam elements, as shown in Figure 6(b). This representation was necessary since data defining the geometry and dimensions of the tail section were not provided. A separate NASTRAN [14] analysis was performed to determine the distribution of nodal masses to represent the fuel in the wing. In this analysis, solid 
elements were created defined by the upper and lower wing skins, with one element thickness between each skin. The nodes on the bottom skin were fixed. The solid elements were assigned properties with the density of water, and a gravitational loading was applied. The resulting constraint forces on the bottom nodes were converted into concentrated masses at each node. Once this analysis was completed, the concentrated masses determined from the NASTRAN analysis were copied into the LS-DYNA model.

All of the nodes in the aircraft model were given an initial velocity of $-360 \mathrm{in} / \mathrm{s}(-9.14 \mathrm{~m} / \mathrm{s})$. For the impact surface, all of the edge nodes were constrained from translational and rotational motion. The model was executed in LS-DYNA (version 970) for 0.25 seconds of simulation time, which required 93 hours of CPU time on a single processor Hewlett Packard workstation x4000.

As a quality check on the model, the total weight and longitudinal CG location of the model were compared with those of the test article. The weight of the full-loaded and instrumented aircraft prior to the test was $33,200 \mathrm{lb} .(15,060 \mathrm{~kg})$ and the total weight of the aircraft model was $33,120 \mathrm{lb} .(15,023$ $\mathrm{kg})$, just $80 \mathrm{lb}$. (36.3 kg) lighter than the test article. The measured longitudinal CG position of the test article was 469.2 in. $(11.92 \mathrm{~m})$ from the reference location. For the model, the longitudinal CG position was $471.5 \mathrm{in} .(11.98 \mathrm{~m})$ from the reference location, less than 3 inches $(.076 \mathrm{~m})$ from the experimental value.

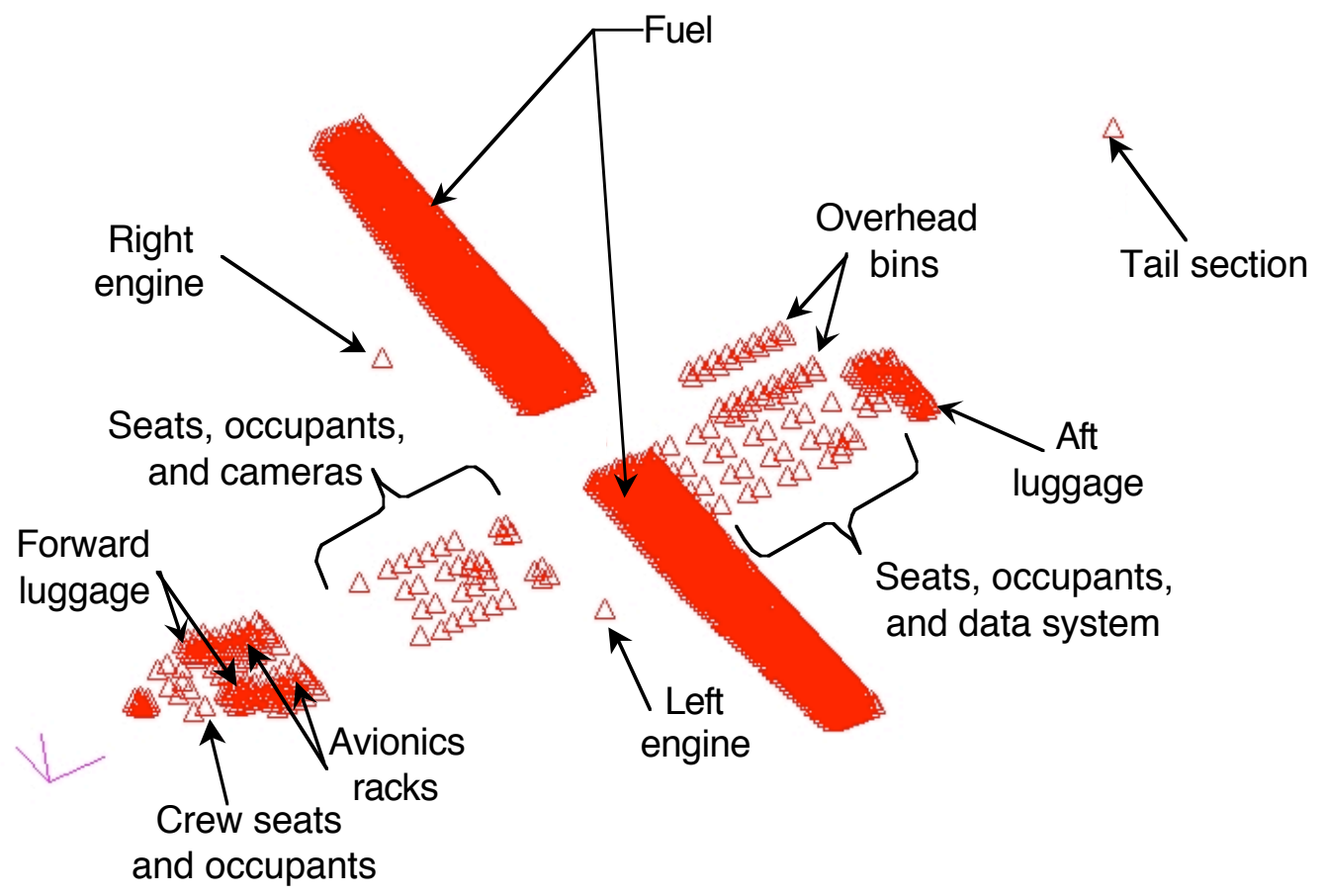

Figure 7. The location of point elements in the model.

\section{TEST-ANALYSIS CORRELATION}

The test-analysis correlation consists of comparisons of experimental and predicted structural deformation and selected acceleration and velocity time-history responses.

\section{Comparison of Structural Deformation}

Comparisons of test article and model deformations are shown in Figure 8 from 0.05 - to 0.25 -seconds in .05 -second intervals. The pictures of model deformation were obtained from the post-processing file, and the experimental pictures were captured from the high-speed film. In general, the model accurately predicts the structural deformation and failure behavior of the test article, including collapse and failure of the fuselage structure beneath the wing. In the experiment, structural failure is 
initiated by fracture of the fuselage frames at FS 25 and FS 27, and is not caused by failure of the "dog bone" beams. The same failure behavior is observed in the model, as shown in Figure 9. This figure shows the predicted deformation of the fuselage frames at FS 25 and FS 27, along with the "dog bone" beams and the wing attachments, at the beginning and end of the simulation. In the model, the frames are highly deformed and fractured, while the "dog bone" beams remain intact. Note that in LS-DYNA, failed elements are removed from the model. The frame failures allow the wing to translate downward through the fuselage cabin. Some differences in structural deformation between the test and analysis are observed. In the model, the wing tips exhibit significant vertical deformation due to flexure of the wing and inflection resulting from formation of a plastic hinge at the wing root. Conversely, only minor oscillatory bending of the wing is observed in the experiment. These deformations are in addition to the rigid body translation of the wing.

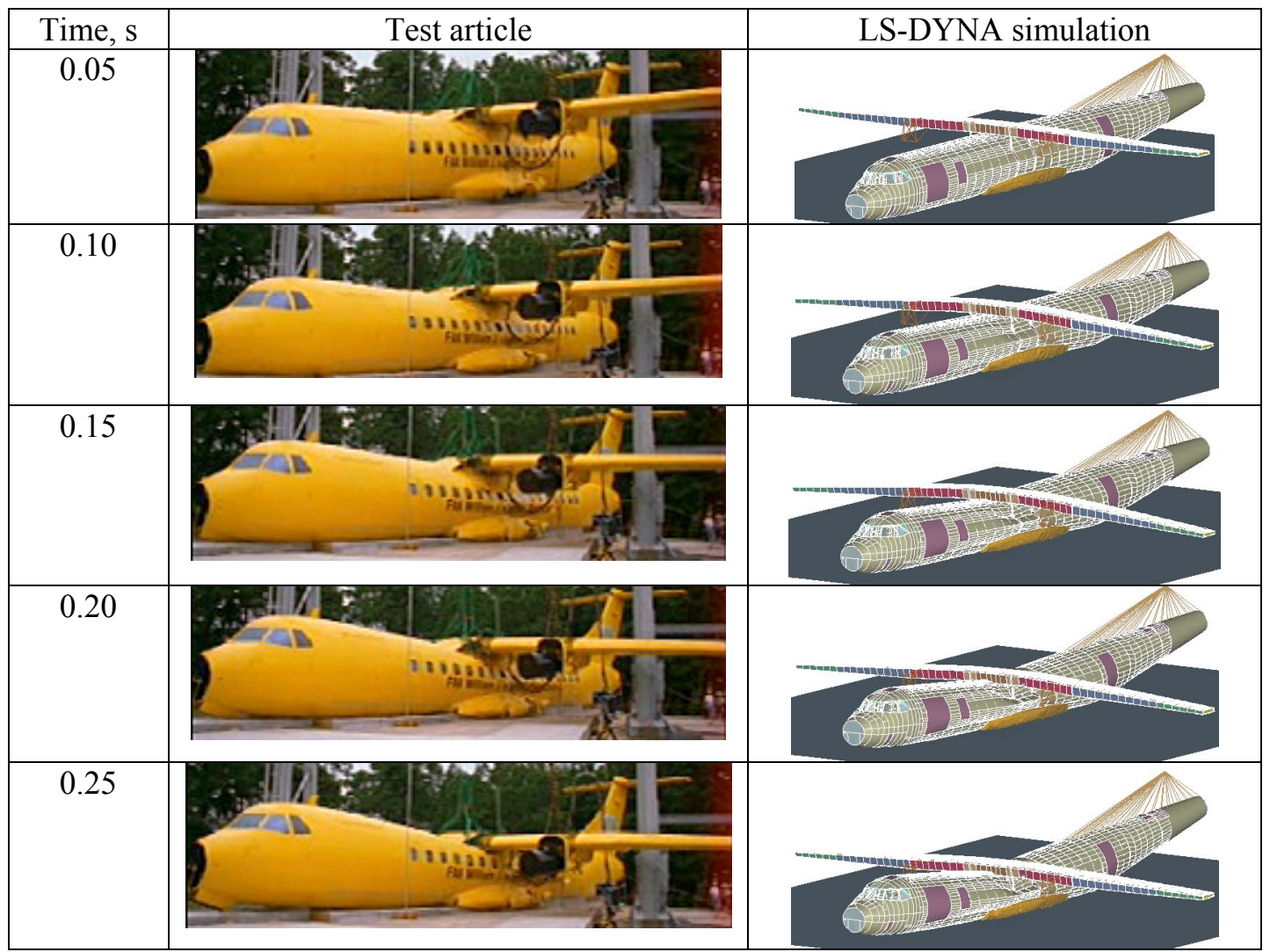

Figure 8. Comparison of structural deformation.

\begin{tabular}{|c|c|}
\hline Time $=0.00 \mathrm{~s}$ & Time $=0.25 \mathrm{~s}$ \\
\hline &
\end{tabular}

Figure 9. Predicted deformation of the fuselage frames (FS 25 and FS 27) that support the wing at times 0.00 - and 0.25 -seconds. 


\section{Comparison of Selected Time-History Responses}

The raw experimental acceleration data were plotted versus time, integrated to obtain the velocity time-history responses, and filtered using a low-pass digital filter based on the SAE J211/1 specifications [15]. A variety of cut-off frequencies were applied in an attempt to obtain a welldefined acceleration pulse, while at the same time not distorting the integrated velocity response. Distortion in the velocity response is determined by comparing the velocity time-histories obtained by integrating the raw and filtered experimental acceleration data. A low-pass cut-off frequency of 33.2 $\mathrm{Hz}$ was selected because it generally met these criteria. All of the experimental and analytical acceleration time-histories shown in the paper are filtered using this cut-off frequency. Also, since minimal distortion was evident, the experimental and analytical velocity responses shown in the paper were obtained by integration of the filtered acceleration data.

The experimental and analytical acceleration and velocity responses of the left outer seat track at FS 20 are shown in Figure 10. For the test, the acceleration response exhibits two main peaks, as indicated in Figure 10 (a). The first acceleration peak $(18 \mathrm{~g})$ is smaller in magnitude than the second $(28 \mathrm{~g})$. At this location, the predicted acceleration response also exhibits two peaks; however, the first peak is higher in magnitude ( $28 \mathrm{~g})$ than the second $(17 \mathrm{~g})$. The filtered experimental and analytical acceleration data were integrated to obtain the velocity responses plotted in Figure 10 (b). Both curves are closely matched up to 0.06 seconds. After that time, the analytical velocity response crosses zero velocity at 0.075 seconds and exhibits a rebound of about $34 \mathrm{in} / \mathrm{s}(0.86 \mathrm{~m} / \mathrm{s})$. Whereas the experimental response flattens out after 0.06 seconds and does not cross zero until 0.15 seconds. The maximum rebound velocity exhibited by the experimental response is $30 \mathrm{in} / \mathrm{s}(0.76 \mathrm{~m} / \mathrm{s})$.

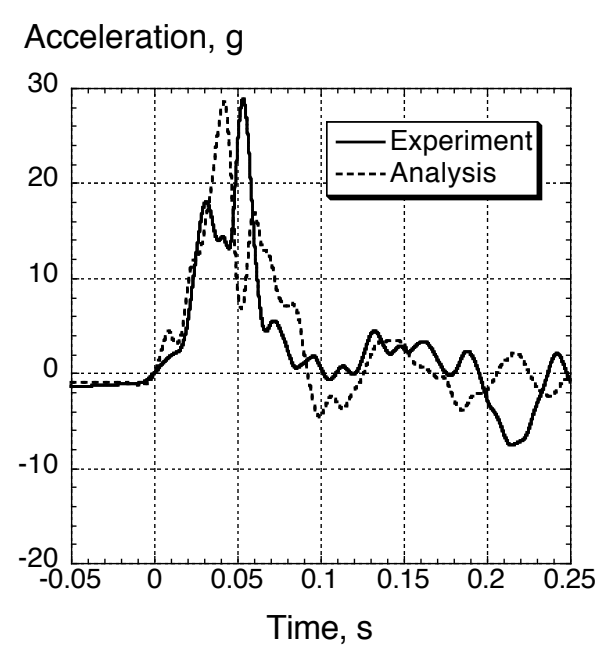

(a) Acceleration response.

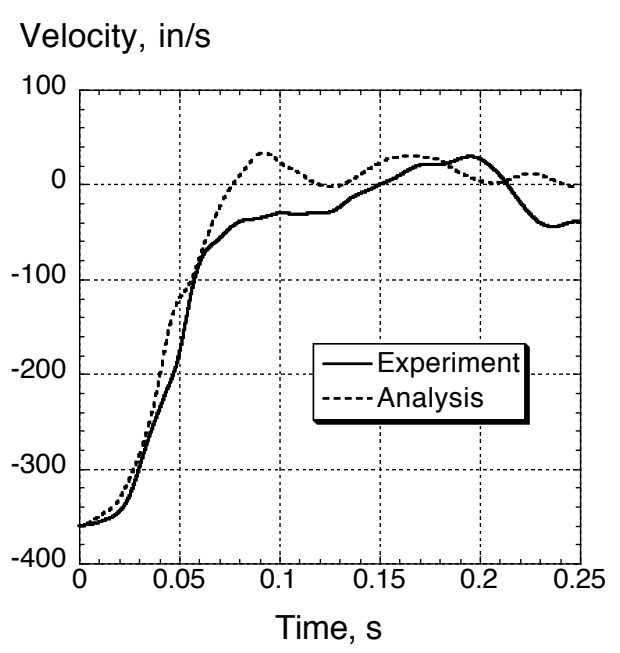

(b) Velocity response.

Figure 10. Experimental and analytical time-history responses for the left outer seat track at FS 20.

The experimental and analytical acceleration and velocity responses of the right outer seat track at FS 18 are shown in Figure 11. For this location, the peak acceleration values for the test and analysis are of the same magnitude, about $24 \mathrm{~g}$. Also, the predicted velocity response closely matches the experimental response, i.e. both curves cross zero velocity at the same time (.08 seconds) and exhibit approximately the same rebound velocity of $50 \mathrm{in} / \mathrm{s}(1.27 \mathrm{~m} / \mathrm{s})$.

Next, the experimental and analytical acceleration and velocity responses of the right side of the cockpit floor are plotted in Figure 12. Again, the experimental acceleration response exhibits two peaks; however, in this case the first peak $(34 \mathrm{~g})$ is higher in magnitude than the second $(28 \mathrm{~g})$. The predicted peak acceleration is $26 \mathrm{~g}$. The experimental pulse is shorter in duration than the analytical response by about 0.02 seconds, as indicated in the velocity plot of Figure 12 (b). However, both curves exhibit the same rebound velocity of $90 \mathrm{in} / \mathrm{s}(2.29 \mathrm{~m} / \mathrm{s})$. 


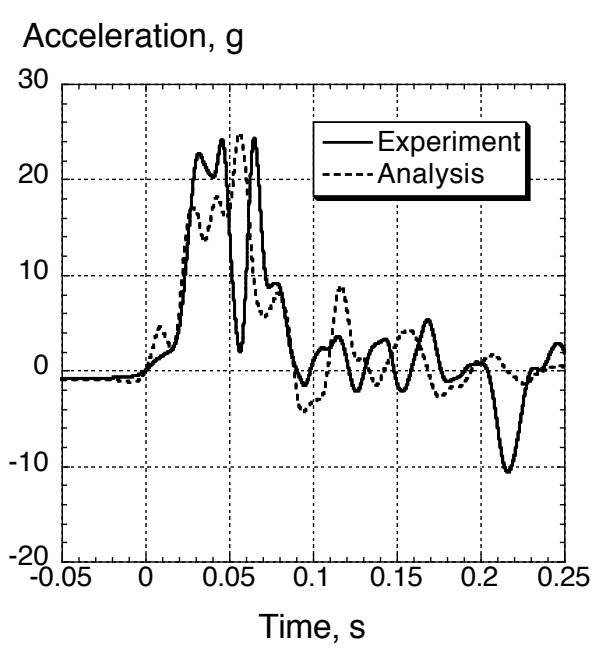

(a) Acceleration responses.

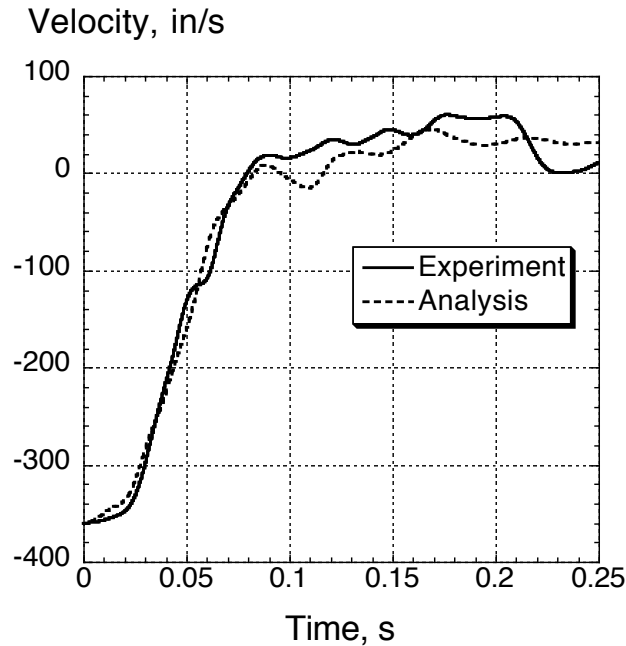

(b) Velocity responses.

Figure 11. Experimental and analytical time-history responses for the right outer seat track at FS 18.

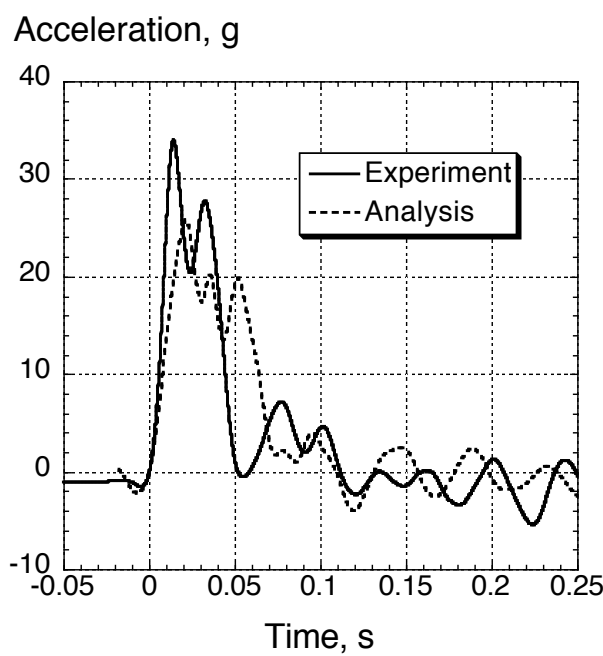

(a) Acceleration responses.

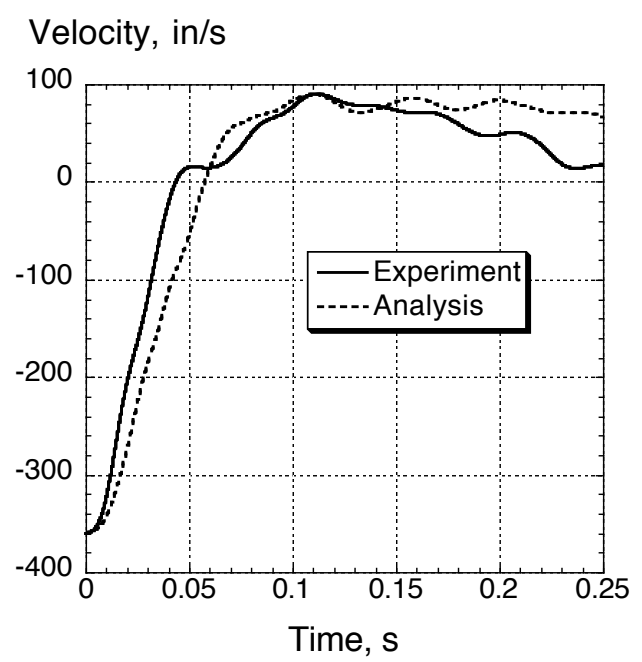

(b) Velocity responses.

Figure 12. Experimental and analytical time-history responses of the right side of the cockpit floor.

The experimental and analytical acceleration and velocity responses of the left inner seat track at FS 29 and the right inner seat track at FS 35 are plotted in Figures 13 and 14, respectively. The locations of these accelerometers are shown in the schematic drawing of Figure 2. The accelerometer at FS 29 is located on the floor slightly to the rear of the fuselage frames supporting the wings, while the accelerometer at FS 35 is located on the floor at the very rear of the aircraft. At these two locations, the filtered experimental acceleration responses exhibit high-amplitude, low frequency responses, making it difficult to discern a well-defined acceleration pulse. In general, the predicted acceleration responses match the peak values and the pulse durations of the experimental acceleration responses at these two locations. However, the comparison of the velocity responses is, perhaps, a better measure of the level of correlation, as shown in Figures 13(b) and 14(b).

The experimental and predicted acceleration and velocity responses of the center of the tail section at FS 47 are plotted in Figure 15. Unlike the floor acceleration responses, most of which had pulse durations of 0.1 second or less, this response is 0.2 seconds in duration. Both the experimental and analytical acceleration responses exhibit a single pulse, of approximately the same duration and magnitude. The experimental and analytical velocity responses, shown in Figure 15 (b), show nearly perfect agreement, with both curves crossing zero velocity at nearly the same time ( 0.16 seconds) and exhibiting a maximum rebound velocity of $147 \mathrm{in} / \mathrm{s}(3.73 \mathrm{~m} / \mathrm{s})$ at 0.21 second. 
Acceleration, $\mathrm{g}$

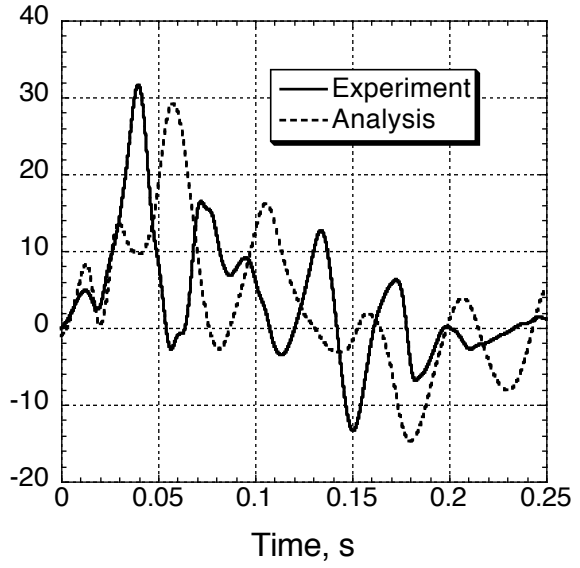

(a) Acceleration responses.

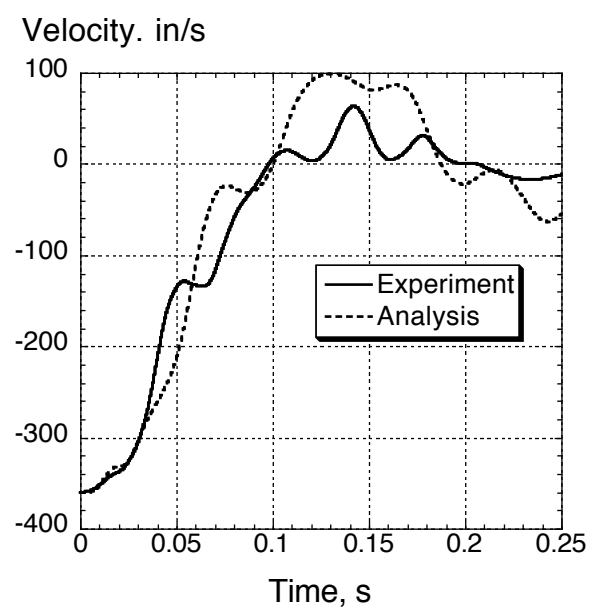

(b) Velocity responses.

Figure 13. Experimental and analytical time-history responses of the left inner seat track at FS 29.

Acceleration, $g$

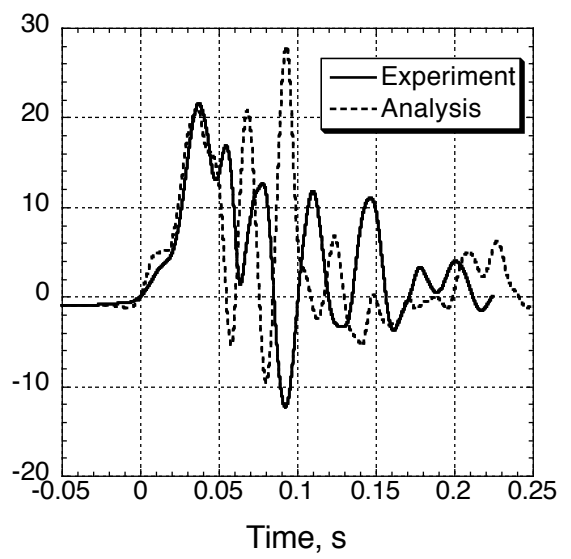

(a) Acceleration responses.

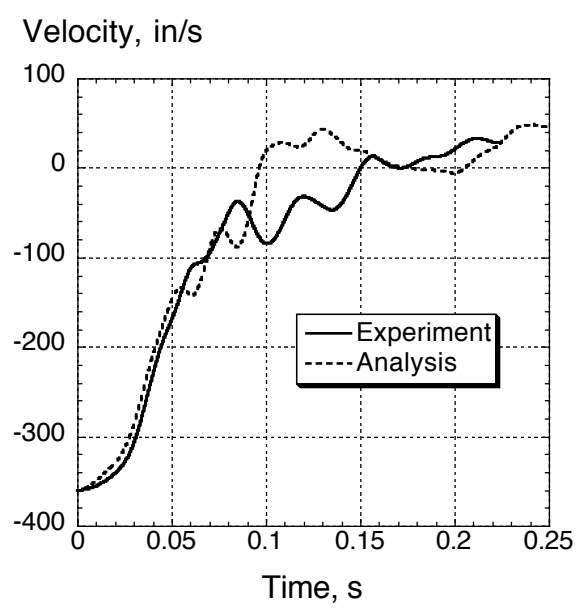

(b) Velocity responses.

Figure 14. Experimental and analytical time-history responses of the right inner seat track at FS 35.

Acceleration, $g$

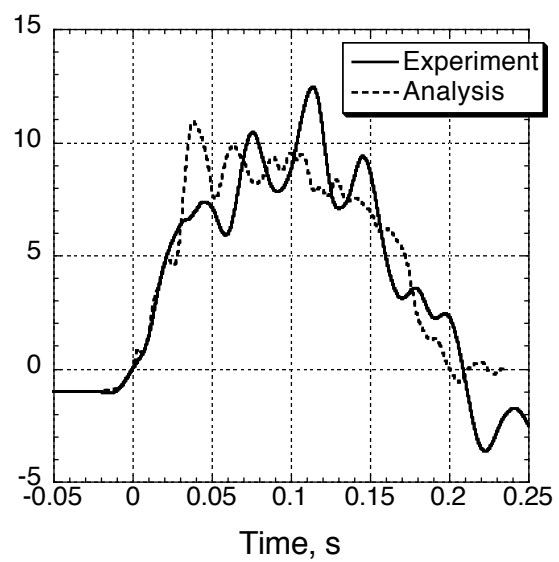

(a) Acceleration responses.

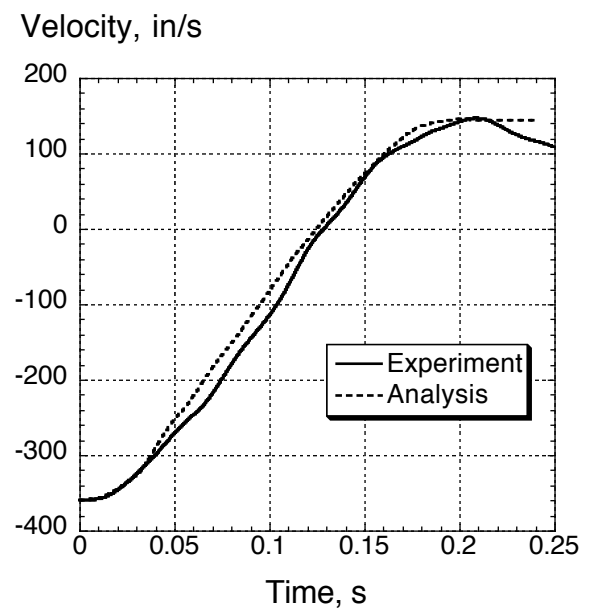

(b) Velocity responses.

Figure 15. Experimental and analytical time-history responses of the center tail section at FS 47.

The experimental and analytical acceleration and velocity responses of the left sidewall at FS 18 are plotted in Figure 16. This accelerometer was located on the sidewall approximately $12 \mathrm{in} .(0.305 \mathrm{~m})$ above the floor and was oriented in the vertical direction. The analytical acceleration response closely 
matches the magnitude (peak acceleration of $26.5 \mathrm{~g}$ 's for the analysis compared with $22.5 \mathrm{~g}$ 's for the experiment) of the experimental pulse. The velocity responses for the test and analysis, shown in Figure 16 (b), are close up to 0.075 seconds, after which time the analytical curve crosses zero velocity at 0.08 seconds and exhibits a maximum rebound velocity of $36 \mathrm{in} / \mathrm{s}(0.91 \mathrm{~m} / \mathrm{s})$. However, the experimental response flattens out and does not cross zero velocity until 0.12 seconds, after which it exhibits a prolonged rebound velocity of $60 \mathrm{in} / \mathrm{s}(1.52 \mathrm{~m} / \mathrm{s})$, not seen in the analytical curve.

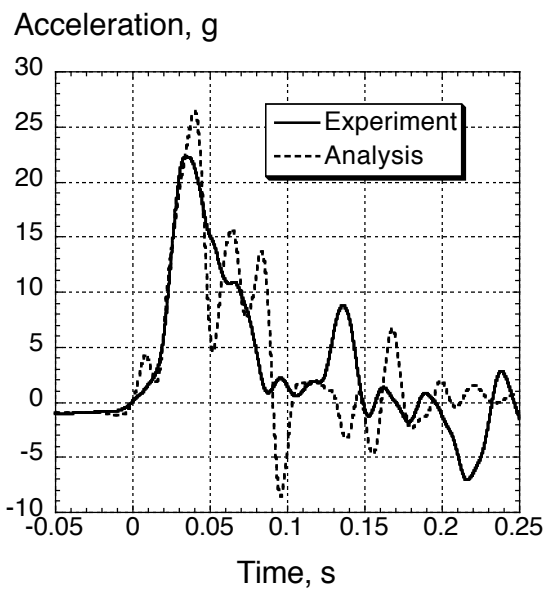

(a) Acceleration responses.

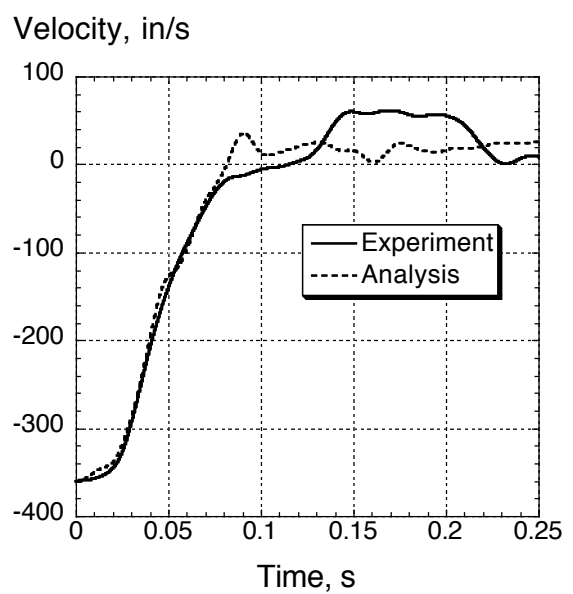

(b) Velocity responses.

Figure 16. Experimental and analytical time-history responses of the left sidewall at FS 18.

The final time-history comparison is shown in Figure 17, in which the experimental and analytical acceleration and velocity responses of the center ceiling at FS 26 are plotted. The position of this accelerometer is at the center of the bottom skin of the wing. The filtered experimental and analytical acceleration data contain high-amplitude, low frequency responses and it is not possible to see a welldefined acceleration pulse. The predicted acceleration response overshoots the magnitude of the initial peak acceleration of the experimental response; however, it accurately captures the dip and subsequent rise in the experimental response that occurs at approximately 0.1 seconds. At this accelerometer location, the analytical response appears to be reducing velocity more quickly that the experiment, as shown in Figure 17 (b). For example, at 0.04 seconds, the experimental velocity is $-289 \mathrm{in} / \mathrm{s}(7.34 \mathrm{~m} / \mathrm{s})$, while the predicted velocity is $-204 \mathrm{in} / \mathrm{s}(5.18 \mathrm{~ms} /)$. Also, note that neither response has crossed zero velocity by 0.25 seconds indicting that the wing is still translating downward.

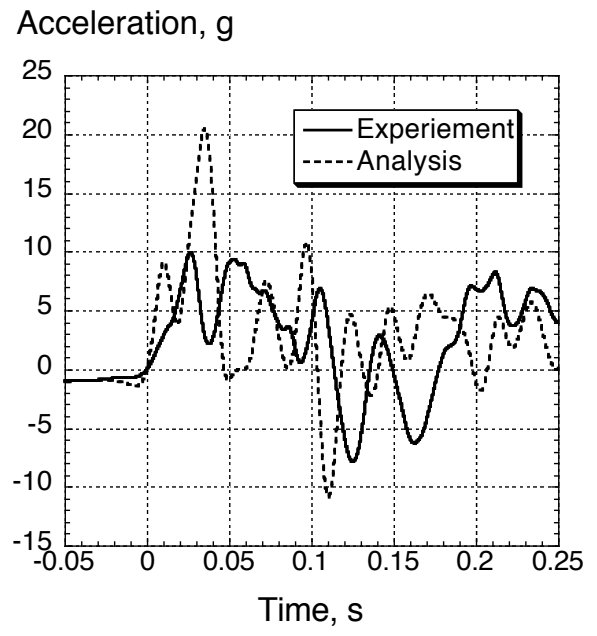

(a) Acceleration responses.

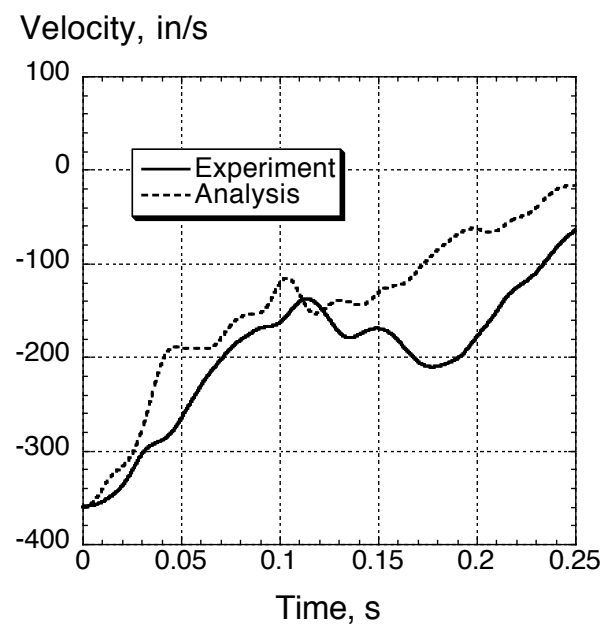

(b) Velocity responses.

Figure 17. Experimental and analytical time-history responses of the ceiling at FS 26. 


\section{DISCUSSION OF RESEULTS}

In general, a high level of agreement was obtained between the experimental and analytical data, especially when considering the complexity of the test article. The simulation accurately predicted the major structural failure, the collapse and failure of the fuselage frames supporting the wing structure. However, some differences in the experimental and analytical structural deformation were observed. The model exhibited more bending of the wing than was observed experimentally, due in part to the development of an inflection point or plastic hinge at the wing root. This difference in behavior indicates that the material properties and/or average dimensions used in the model should be modified to increase the structural stiffness of the wing to better match that of the test article.

The model predicted the experimental acceleration and velocity time-histories quite well. The high level of agreement achieved for the floor-level acceleration responses is important in that these pulses are transmitted to the seats and occupants during a crash. Also, these data are needed to accurately assess dynamic seat criteria for commuter-class aircraft. It was noted that even after filtering, some of the acceleration responses exhibited high-amplitude, low frequency responses, making it difficult to obtain a well-defined acceleration pulse. For other channels, the low-pass filter with a cut-off frequency of $33.2 \mathrm{~Hz}$ was able to generate a concise acceleration pulse. Thus, for this test, it may be necessary to use different cut-off frequencies when filtering the data, on a channel-by-channel basis. Of course, the analytical data would be filtered at the same frequency as the experimental data at each location.

\section{CONCLUDING REMARKS}

A full-scale three-dimensional finite element model of a twin-turboprop high-wing commuter-class aircraft, the ATR42-300, was developed and executed as a crash simulation. The analytical predictions were correlated with test data obtained from a $30-\mathrm{ft} / \mathrm{s}(9.14 \mathrm{~m} / \mathrm{s})$ vertical drop test of the aircraft that was conducted using the Dynamic Drop Test Facility at the FAA William J. Hughes Technical Center in Atlantic City, NJ. For the test, the aircraft was configured with seats, anthropomorphic test dummies, luggage in the forward and aft compartments, and 8,700-lb. (3,946 $\mathrm{kg}$ ) of water in the wings to represent the fuel loading. The finite element model of the aircraft was developed from direct measurements of the airframe geometry and contained 57,643 nodes and 62,979 elements including 60,197 quadrilateral shell elements; 551 triangular shell elements; 526 beam elements; and, 1,705 point elements. The model was executed in LS-DYNA, a commercial code for performing explicit transient dynamic simulations.

The analytical predictions correctly simulated the major damage mode seen during the test, which was collapse and failure of the fuselage structure beneath the wing. These structural failures allowed the wing to displace vertically through the fuselage cabin. In general, a high level of agreement was obtained between the experimental and analytical data, especially when considering the complexity of the test article. It was particularly important to obtain accurate prediction of the floor-level acceleration responses, since these pulses are transmitted to the seat and occupants. These data will be useful in evaluating the FAA's proposed dynamic seat standards for commuter-class aircraft.

\section{ACKNOWLEDGEMENTS}

The authors acknowledge Gary Frings, Allan Abramowitz, Tong Vu, and Tim Smith of the FAA for their assistance with the geometry model development, and for providing the test data, pre- and posttest photographs, and videos of the test. Also, we acknowledge the support of Alan Stockwell and Hasan Abu-Khajeel of Lockheed Martin Space Operations at NASA Langley Research Center for their assistance with model discretization. 


\section{REFERENCES}

1. Noor, A., and Carden H. C., editors, "Computational Methods for Crashworthiness," NASA Conference Publication 3223, October 1993.

2. Abramowitz, A., Smith, T. G, Vu, T., "Vertical Drop Test of a Narrow-Body Transport Section with a Conformable Auxiliary Fuel Tank Onboard.” DOT/FAA/AR-00/56, October 2000.

3. Abramowitz, A., Smith, T. G., Vu, T., Zvanya, J. R., "Vertical Drop Test of a Narrow-Body Transport Fuselage Section with Overhead Stowage Bins," DOT/FAA/AR-01/100, September 2002.

4. Anon., "MSC.Dytran User’s Manual Version 4.7,” The MacNeal-Schwendler Corporation, Los Angeles, CA, 1999.

5. Jackson, K. E. and Fasanella, E. L., "Crash Simulation of a Vertical Drop Test of a B737 Fuselage Section with Overhead Bins and Luggage," Proceedings of the Third Triennial Aircraft Fire and Cabin Safety Conference, Atlantic City, NJ, October 22-25, 2001.

6. Fasanella, E. L. and Jackson, K. E., "Crash Simulation of a Vertical Drop Test of a B737 Fuselage Section with an Auxiliary Fuel Tank," Proceedings of the Third Triennial Aircraft Fire and Cabin Safety Conference, Atlantic City, NJ, October 22-25, 2001.

7. Jackson, Karen E. and Fasanella, E. L., "Crash Simulation of Vertical Drop Tests of Two Boeing 737 Fuselage Sections," DOT/FAA/AR-02/62, August 2002.

8. Anon., “MSC.PATRAN,” Publication No. 903077, Version 6, The MacNeal-Schwendler Corporation, 1996.

9. Anon., "LS-DYNA Keyword User's Manual," Version 970, Livermore Software Technology Company, Livermore, CA, April 2003.

10. Anon., "Weight and Balance Manual," Avions de Transport Regional, Service Bulletin No. ATR42-34-0114, issued March 1992.

11. Jackson, K. E., and Fasanella, E. L., "Development of an LS-DYNA Model of an ATR42-300 Aircraft for Crash Simulation" Proceedings of the Eighth International LS-DYNA Users Conference, May 2-4, 2004 in Dearborn, MI.

12. Military Handbook 5H, U.S. Department of Defense, 1 December 1998.

13. Anon., "LS-PRE/POST v. 1.0 Manual” Livermore Software Technology Company, Livermore, CA, August 27, 2002.

14. Anon, "MSC/NASTRAN Quick Reference Guide," Version 70.5, The MacNeal-Schwendler Corporation, Los Angeles, CA, February 1998.

15. Society of Automotive Engineers, Recommended Practice: Instrumentation for Impact Test - Part 1, Electronic Instrumentation, SAE J211/1, March 1995. 